\title{
Etnoekologi Tanaman Budidaya di bawah Naungan Pinus (Pinus merkusii Jungh. \& De Vriese) di Desa Duwet Kedampul, Kecamatan Tumpang, Kabupaten Malang
}

\author{
Retno Oktaviani ${ }^{1)}$, Jati Batoro ${ }^{2)}$ \\ ${ }^{1,2)}$ Laboratorium Taksonomi, Struktur dan Perkembangan Tumbuhan, Program Studi Biologi, Jurusan Biologi, \\ Fakultas Matematika dan IImu Pengetahuan Alam, Universitas Brawijaya \\ Alamat korespondensi: ${ }^{2)}$ jati_batoro@yahoo.co.id
}

\begin{abstract}
ABSTRAK
Pengetahuan lokal secara substansial merupakan norma yang berlaku dalam suatu masyarakat yang diyakini kebenarannya dan menjadi acuan dalam bertindak dan berperilaku sehari-hari. Desa Duwet Kedampul dihuni oleh masyarakat Magersari yang bermata pencaharian dari sektor pertanian dengan melakukan teknik pengelolaan lahan tertentu pada lahan di bawah naungan pinus. Teknik pengelolaan tersebut merupakan pengetahuan lokal yang perlu dikaji dengan studi etnoekologi. Penelitian ini bertujuan mengetahui kegiatan pengelolaan lahan, keanekaragaman jenis tumbuhan, dan bentuk pemanfaatan tumbuhan yang dilakukan oleh masyarakat Magersari di Desa Duwet Kedampul. Pada penelitian ini dilakukan wawancara bebas dan semi-terstruktur terhadap narasumber, inventarisasi jenis tumbuhan dan pengukuran parameter lingkungan pada lahan di bawah naungan pinus. Hasil wawancara dianalisis secara deskriptif dan penghitungan nilai kegunaan (UVs). Hasil inventarisasi dianalisis dengan penghitungan nilai INP (Indeks Nilai Penting). Hasil penelitian menunjukkan bahwa masyarakat Magersari di Desa Duwet Kedampul menerapkan sistem penanaman tumpang sari, penanaman berdasarkan musim, pembuatan terasiring, pembuatan teras bangku, dan pemangkasan tajuk atau perempesan pinus. Hasil perhitungan INP menunjukkan bahwa Ageratum conyzoides memiliki nilai INP tertinggi. Pada perhitungan pendugaan UVs diketahui bahwa pisang (Musa paradisiaca) merupakan jenis tanaman yang memiliki UVs tertinggi.
\end{abstract}

Kata kunci: Nilai Penting, nilai kegunaan, pengelolaan lahan, pengetahuan lokal, pinus

\section{ABSTRACT}

Local knowledge is the norms that is substantially prevailed in a society and believed to be true, and become a reference in the everyday act and behave. Duwet Kedampul Village inhabited by the Magersari people who worked in agricultural sectors by applying specific techniques of land management on the shaded pine land. The management techniques which were rise from local knowledge needed to be assessed by the ethnoecology study. Therefore, this study aimed to understand the land management, plant species diversity, and alternative utilization of plants by the Magersari community in the Duwet Kedampul Village. The free interviews and semi-structured interview were conducted to the people as well as an inventory of plant and measurement of environmental parameters on the shaded pine land. The interview results were descriptively analyzed and the value of usability (UVs) were calculated. The results also were analyzed by calculating the value of inventory IVI (Importance Value Index). The results showed that Magersari community in the Duwet Kedampul Village implemented the intercropping system, cropping based on planting season, applied of terracing as well as bench terracing, and trimmed pine canopy. The calculation result showed that Ageratum conyzoides had the highest of IVI. In the estimated calculation of UVs, It was known that banana (Musa paradisiaca) had the highest UVs.

Keywords: The Importance Value Index, the Utility Value, land management, local knowledge, pine

\section{PENDAHULUAN}

Pengetahuan lokal adalah semua bentuk pengetahuan, keyakinan, pemahaman atau etika yang menuntun perilaku manusia dalam kehidupan di dalam komunitas ekologis ${ }^{[5]}$. Pengetahuan lokal dapat berupa nilai, kepercayaan, adat istiadat dan aturan-aturan khusus. Pengetahuan lokal secara substansial merupakan norma yang berlaku dalam suatu masyarakat yang diyakini kebenarannya dan menjadi acuan dalam bertindak dan berperilaku sehar-hari ${ }^{[2]}$. 
Desa Duwet Kedampul dihuni oleh masyarakat Magersari yang bermata pencaharian dari sector pertanian dan penyadapan getah pinus. Lahan yang berada di sekitar desa ini merupakan lahan yang ditanami tanman pokok kehutanan yaitu pohon pinus. Pihak Perhutani menjalin kerjasama dengan masyarakat Magersari di Desa Duwet Kedampul sehingga tercipta peluang bagi masyarakat untuk mengelola lahan tersbut dengan menanam tanaman budidaya di bawah naungan pohon pinus.

Keterbatasan lahan, pertumbuhan penduduk dan kebutuhan ekonomk merupakan beberapa permasalahan yang dihadapi masyarakat terkait dengan pengelolaan lahan dan pemanfaatan tumbuhan di bawah naungan pohon pinus. Permasalahan tersebut telah mendorong masyarakt untuk melakukan teknik tertentu dalam pengelolaan lahan dan bentuk pemanfaatan tumbuhan. teknik pengelolaan dan pemanfaatan tersebut merupakan pengetahuan lokal yang dimiliki masyarakat Magersari di Desa Duwet Kedampul yang perlu dikaji denga studi etnoekologi.

Penelitian ini bertujuan untuk mengetahui kegiatan pengelolaan lahan, keanekaragaman jenis tumbuhan, dan bentuk pemanfaatan tumbuhan di bawah naungan pinus yanf dilakukan oleh masyarakat Magersari di Desa Duwet Kedampul.

\section{METODE PENELITIAN}

\section{Tempat Penelitian}

Penelitian dilakukan di Desa Duwet Kedampul, Kecamatan Tumpang, Kabupaten Malang. Analisis data dilakukan di Laboratorium Taksonomi, Struktur dan Perkembangan Tumbuhan serta Laboratorium Ekologi dan Diversitas Hewan, Jurusan Biologi, Fakultas Matematikan dan Ilmu Pengethuan Alam, Universitas Brawijaya, Malang.

\section{Wawancara}

Pada penelitian ini dilakukan wawancara bebas dan semi-terstruktur terhadap narasumber. Wawancara terhadap narasumber terkait dengan teknik pengelolaan lahan dan pemanfaatan tumbuhan di bawah naungan pinus yang dilakukan oleh masyarakat.

\section{Pengukuran Parameter Lingkungan di Bawah Naungan Pinus}

Pengukuran nilai parameter lingkungan dilakukan di masing-masing plot pengamatan. Parameter lingkungan yang diukur adalah temperature udara, ketinggian tempat, temperature tanah, kelembaban tanah, kadar Bahan Organik Tanah (BOT) dan $\mathrm{pH}$ tanah.

\section{Inventarisasi Tumbuhan Bawah Liar di Bawah Naungan Pinus}

Pada penelitian ini, inventarisasi tumbuhan bawah dilakukan dengan metode plotting. plotplot pengamatan dibuat dengan ukuran $2 \times 2 \mathrm{~m}^{2}$ sebanyak 10 plot dengan peletakan plot dilakukan secara acak.

\section{Analisi Data}

Hasil wawancara terhadap narasumber terkait teknik pengelolaan lahan dianalisis secara deskriptif sedangkan hasil wawancara terkait bentuk pemanfaatan tumbuhan di bawah naungan pinus yang dilakukan oleh masyarakat dikompilasi untuk ditentukan nilai kegunaan (Use Valuable atau UVs). Hasil inventarisasi tumbuhan liar di bawah naungan pinus dikompilasi untuk ditentukan nilai INP (Indeks Nilai Penting) tumbuhan bawah liar di bawah naungan pinus.

\section{HASIL DAN PEMBAHASAN}

\section{Masyarakat Magersari di Desa Duwet Kedampul}

Magersari adalah komunitas-komunitas penduduk di dalam kawasan hutan Negara. Masyarakat Magersari di Desa Duwet Kedampul bermata pencaharian utama dari sektor pertanian dan penyadapan getah pinus (Gambar 1). Getah pinus dapat dijadikan terpentin dan gondorukem. Gondorukem digunakan dalam industry batik sedangkan terpentin digunakan sebagai pelarut minyak cat dan lak. Produksi getah pinus dipengaruhi oleh faktor internal dan eksternal. Faktor internal yaitu jenis pohon, diameter batang dan keadaan tajuk. Faktor eksternal berasal dari lingkungan dan perlakuan sadapan yang dilakukan ${ }^{[7]}$. Teknik sadapan yang dilakukan oleh penyadap di Desa Duwet Kedampul adalah teknik kuare. Pada satu kuare denan keadaan normal dapat menghasilkan 4-5 gram/hari dengan harga getah pinus sebesar Rp. $3.500 / \mathrm{kg}$. 


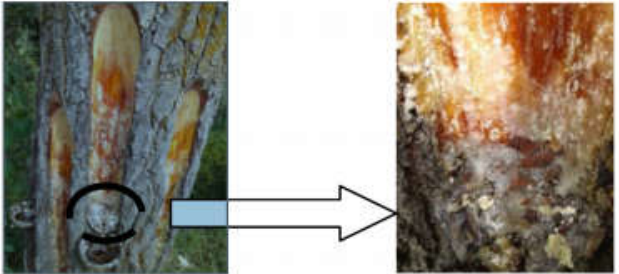

Gambar 1. Penyadapan getah pinus

\section{Kerjasama antara Pihak Perhutani dan Masyarakat Magersari di Desa Duwet Kedampul}

Lahan di Desa Duwet Kedampul merupakan lahan yang ditanami tanaman pokok kehutanan seperti pinus. Perhutani merupakan suatu badan umum milik Negara yang diberi wewenang untuk menyelenggarakan kegiatan pengelolaan sumber daya pada lahan hutan tersebut ${ }^{[8]}$. Pada penyelenggaraan kegiatan tersebut, pihak Perhutani memberdayakan masyarakat Magersari dengan mengajak masyarakat untuk bekerja sebagai penyadap getah pinus.

Faktor keterbatasan lahan, pertumbuhan penduduk dan kebutuhan ekonomi merupakan beberapa faktor yang mendasari penggunaan lahan di bawah naungan pinus. Penggunaan lahan tersebut untuk ditanami tanaman budidaya seperti sayuran yang dimulai sejak tahun 1998, dan disebut sebagai lahan komplangan. Pengelolaan lahan di bawah naumga pinus dapat dilakukan masyarakat dengan syarat masyarakat harus menjaga keamanan pinus dan mengolah lahan tanpa merusak ekosistem hutan serta pada petak yang ditanami tanaman budidaya tersebut terdapat warga yang bertanggung jawab dalam melakukan penyadapan getah pinus. Pihak Perhutani tidak meminta bayaran atas kegiatan pengeloaan lahan yang dilakukan oleh masyarakat.

\section{Pengelolaan Lahan di Bawah Naungan Pinus}

Pada penelitian ini diketahui bahwa tanaman yang dibudidayakan di bawah naunga pinusadalah bwang prei, buncis, cabe keriting, cabe rawit, jagung, jahe, kopi, kubis, papaya, pisang, rumput gajah, singkong, talas mbothe, talas bentul dan tomat. Pada kegiatan pengelolaan lahan perlu dipertimbangkan tingkat kesuburan tanah, kemiringan, ketinggian dan jarak dari pemukiman. Pengelolaan lahan yang tidak subur ditandai dengan tanah yang berwarna kuning dan tang yang berstruktur keras sedangkan lahan yang subur ditandai dengan tanah yang berwarna hitam/gelap dengan tekstur halus. Berikut ini merupakan kegiatan yang dilakukan masyarakat dalam mengelola lahan di bawah naungan pinus, yaitu:

a. Persiapan lahan

Langkah yang dilakukan adalah mencangkuli tanah dan dibalik, kemudian bongkahan tanah dihaluskan dan sisa pertanaman sebelumnya dibersihkan agar tidak menjadi sumber penyakit. Langkah selanjutnya dibuat bedengan pada lahan tersebut dan pemberian mulsa plastik untuk mengurangi kompetisi tanaman budidaya dengan tumbuhan bawah liar dan mempertahankan kelembaban tanah.

Pada lahan di Desa Duwet Kedampul yang berkontur cukup curam diterapkan sistem terasiring yang dilakukan untuk menghindari tanah longsor dan erosi. Selain itu, teras bangku merupakan bentuk yang sering diterapkan pada pengelolaan lahan di adesa Duwet Kedampul. Teras bangku atau teras tangga dibuat dengan cara memotong panjang lereng dan meratakan tanah di bagian bawahnya sehinggan membentuk seperti tangga. Teras bangku secara teknis merupakan suatu teknik pengendalian erosi yang efektif. Efektivitas tersebut dapat ditingkatkan dengan tanaman penguat teras di bibir dan tampingan teras ${ }^{[1]}$.

b. Penanaman

Masyarakat Magersari melakukan penanaman berdasarkan musim yaitu musim hujan dan kemarau. Sistem penanaman yang digunakan oleh sebagian besar masyarakat Magersari adalah sistem tumpang sari. Tumpang sari adalah kegiatan penanaman dua jenis tanaman atau lebih di lahan dan waktu yang bersamaan. Hal ini dilakukan untuk meningkatkan produktivitas per satuan luas lahan $^{[11]}$.

c. Pemupukan

Pemberian pupuk biasanya dilakukan hanya dalam satu maupun dua kali dalam setiap satu masa tanam. Pupuk yang digunakan merupakan campuran antara penggunaan pupuk alami dan buatan seperti pupuk urea, ZA, dan NPK.

d. Pemeliharaan tanaman dan penyiangan gulma

Pada tanaman budidaya yang merambat dan mudah rebah memerlukan lanjaran/turus/anjang-anjang agar dapat tumbuh dengan baik. Penyiangan terhadap gulma mulai 
dilakukan pada umur tanaman satu bulan untuk mengurangi kompetisi tanaman dengan gulma dalam mendapatkan unsur hara. Masyarakat juga perlu untuk membersihkan daun-daun pinus yang berjatuhan di lahan komplangan untuk mengurangi resiko menurunnya kualitas dan kuantitas hasil produksi tanaman budidaya masyarakat dikarenakan pinus mengandung senyawa alelopati yaitu pinene dan tannin. Daun pinus yang belum terdegradasi dapat menurunkan pertumbuhan panjang radicula kecambah sawi ${ }^{[6]}$.

\section{e. Pengendalian Organisme Pengganggu Tanaman (OPT)}

Masyarakat menggunakan pestisida untuk mengendalikan OPT yang menyerang tanaman budidaya di bawah naungan pinus. Pestisida yang digunakan oleh masyarakat adalah Curacron 500 EC, Phytoklor 82,5.

f. Pemanenan dan pemasaran hasil produksi tanaman

Hasil panen tanaman budidaya akan dijual pada tengkulak. Pemasaran hasil produksi tanaman selanjutnya akan dijual oleh tengkulak ke pasar terdekat seperti Pasar Tumpang.

\section{g. Pemangkasan tajuk atau perempesan pinus}

Pemangkasan tajuk merupakan alternatif yang digunakan untuk meningkatkan peneriamaan cahaya oleh tanaman budidaya di bawah naungan pinus yang dilakukan oleh masyarakat setiap dua tahun sekali (Gambar 2). Kegiatan pemangkasan tajuk melebihi 50\% dari bagian bawah tajuk pohon pinus. dapat menurunkan hasil produksi getah pinus. Hal ini dikarenakan pemangkasan tajuk berkaitan dengan produksi fotosintesis pada pohon pinus. Pada pemangkasan $50 \%$ bagian bawah tajuk pohon pinus meningkatkan fraksi cahaya lolos sebesar $80 \%$ sehingga meningkatkan laju fotosintesis, luas daun spesifik dan bobot biomassa tanaman jagung ${ }^{[10]}$.

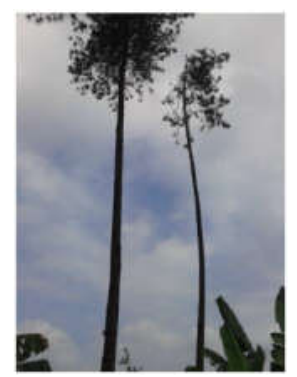

Gambar 2. Pemangkasan tajuk atau perempesan pinus

\section{Parameter Lingkungan di Bawah Naungan Pinus}

Pada penelitian ini diketahui bahwa temperature udara rata-rata di lahan bawah naungan pinus berkisar $22,8^{\circ} \mathrm{C}$ hingga $26,8^{\circ} \mathrm{C}$ dengan temperature tanah rata-rata berkisar $20,0^{\circ} \mathrm{C}$ hingga $26,7^{\circ} \mathrm{C}$. Hasil pengukuran BOT rata-rata pada lahan di naungan pinus berkisar $8,9 \%$ sampai $9,5 \%$ (tergolong tinggi). BOT erat kaitannya dengan kondisi tanah baik secara fisik, kimia dan biologis yang selanjutnya turut menentukan produktivitas suatu lahan ${ }^{[4]}$.

Hasil pengukuran kelembaban tanah ratarata pada lahan di bawah naungan pinus berkisar $33,3 \%$ sampai $70,6 \%$ dengan $\mathrm{pH}$ tanah rata-rata berkisar 4,7 sampai 5,5 (tergolong tanah pada kondisi asam). $\mathrm{pH}$ tanah pada kisaran 4,5-5,5 merupakan kondisi yang mendukung pertumbuhan Pinus merkusii untuk dapat tumbuh optimal. $\mathrm{pH}$ tanah menggambarkan tingkat ketersediaan unsur hara makro maupun mikro dalam tanah yang akan menjadi unsur tersedia bagi pertumbuhan tanaman ${ }^{[9]}$.

\section{Nilai INP}

Jenis tanaman yang memiliki nilai INP tertinggi akan menunjukkan bahwa jenis tersebut paling banyak hidup dan bertahanndi ekosistem tersebut ${ }^{[3]}$. Berdasarkan perhitungan yang dilakukan diketahui bahwa jenis yang memiliki nilai INP tertinggi adalah Ageratum conyzoides (17,25), Panicum repens $(16,97)$, Bidens pilosa $(14,46)$ (Gambar 3). A. conyzoides dan B. pilosa termasuk dalam family Asteraceae sedangkan $P$. repens termasuk dalam family Poaceae. Famili Asteraceae dan Poaceae merupakan family yang memiliki jumlah jenis terbanyak yang ditemukan di bawah naungan pinus.

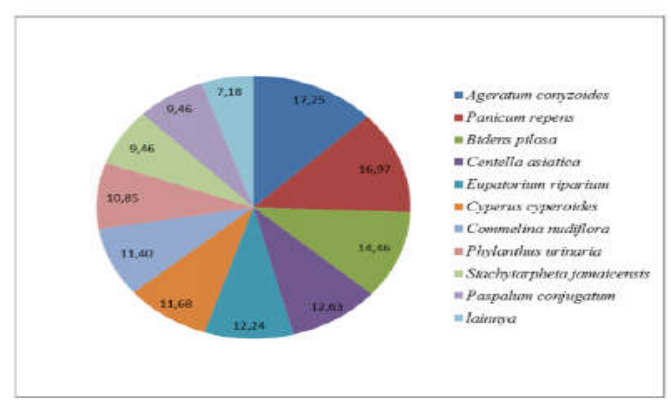

Gambar 3. Nilai INP untuk 10 jenis tumbuhan bawah liar dari 20 jenis yang ditemukan di lahan dibawah naungan pinus 


\section{Nilai UVs}

Berdasarkan wawancara terhadap narasumber diketahui bahwa pada lahan di bawah naungan pohon pinus terdapat 28 jenis tanaman budidaya dan tumbuhan bawah liar yang dimanfaatkan oleh masyarakat Magersari di Desa Duwet Kedampul (Gambar 4). Pemanfaatan terbesar jenis tanaman budidaya oleh masyarakat Magersari adalah dalam kategori sebagai bahan makanan dan bahan upacara adat sedangkan jenis tumbuhan liar dipergunakan dalam kategori sebagai pakan ternak.

Berdasarkan hasil perhitungan nilai UVs diketahui bahwa pisang (Musa paradisiaca) memiliki nilai guna (UVs) yang sangat tinggi sebesar 3,8. Berbagai varietas pisng dapat ditemukan di desa ini, yaitu pisang ambon hijau, ambon kuning, candi, cici, sala roso. Bagian bonggol, daun, buah dan jantung pisang merupakan bagian yang dapat dimanfatkan masyarakat untuk bahan makanan, bahan obatobatan, bahan pembungkus makanan dan keperluan adat. Ritual adat yang dilakukan di Desa Duwet Kedampul adalah bersih desa. Ritual adat bersih desa merupakan ritual yang dilakukan masyarakat sebagai ungkapan rasa syukur atas hasil panen yang baik, bentuk penghormatan terhadap leluhur yang telah meninggal dunia, dan tercukupi sandang pangan serta agar desa terhindar dari bala (bencana).

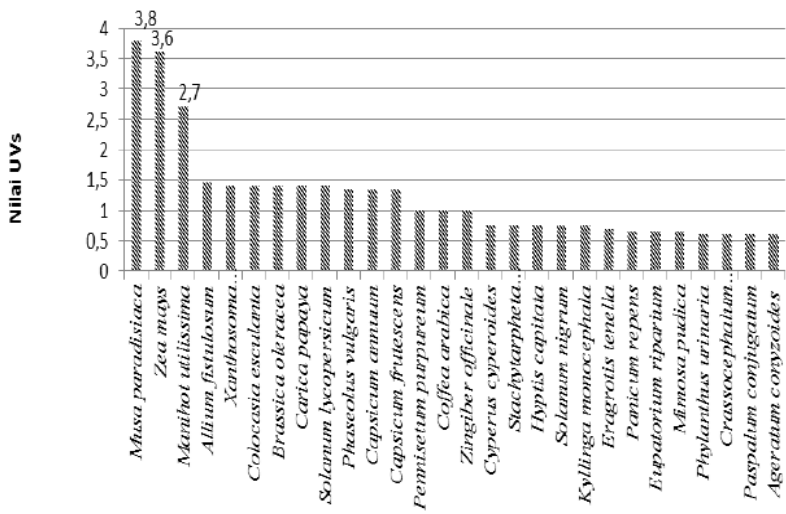

Gambar 4. Nilai UVs tanaman budidaya dan tumbuhan bawah liar yang ditemukan di lahan di bawah naungan pinus.

\section{KESIMPULAN}

Berdasarkan penelitian yang telah dilakukan didapatkan hasil sebagai berikut:

1. Kegiatan pengeloaan lahan di Desa Duwet Kedampul masih secara tradisional. Teknik yang digunakan masyarakat Magersari di
Desa Duwet Kedampul dalam mengelola lahan di bawah naungan pinus adalah penerapan sistem penanaman tumpang sari, penanaman berdasarkan musim, pembuatan terasiring, pembuatan teras bangku dan pemangkasan tajuk atau perempesan pinus.

2. Jenis yang ditemukan di lahan di bawah naungan pinus berjumlah 20 jenis (tumbuhan liar) dan 15 jenis (tanaman budidaya). pada penelitian ini, jenis tumbuhan liar yang memiliki nilai INP tertinggi $(17,25)$ adalah Ageratum conyzoides.

3. Pisang merupakan jenis tanaman yang memiliki UVs tertinggi sebesar 3,8. Bagian bonggol, daun, buah, dan jantung pisang merupakan bagian yang dapat dimanfaatkan masyarakat untuk bahan makanan, bahan obat-obatan, bahan pembungkus makanan dan keperluan adat.

\section{UCAPAN TERIMA KASIH}

Penulis mengucapkan terima kasih kepada Purnomo, S.Si, dan seluruh pegawai BKPH Tumpang, LMDH, masyarakat Magersari Dewa Duwet Kedampul, Hulya Urwati, S.Si dan Is Karima yang telah membantu selama proses penelitian.

\section{DAFTAR PUSTAKA}

[1] Abdurachman, A. dan S. Sutono. 2002. Teknologi Pengendalian Erosi Lahan Belerang. Teknologi Pengelolaan Lahan Kering: Menuju Pertanian Produktif dan Ramah Lingkungan. Pusat Penelitian dan Pengembangan Tanah dan Agroklimat. Bogor.

[2] Geertz, C. 1992. Kebudayaan dan Agama. Kanisius Press Yogyakarta.

[3] Greighsmith, P. 1983. Quantitative Plant Ecology. Blackwell Scientific Publications. Oxford.

[4] Handayani, I.P. 2001. Fraksional Pool Bahan Organik Tanah Labil pada Lahan Hutan dan Lahan Pasca Deforestasi. Jurnal Ilmu-ilmu Pertanian Indonesia. 3(2):75-83.

[5] Keraf, S.A. 2002. Etika Lingkungan. Pn Buku Kompas. Jakarta.

[6] Marisa, H. 1990. Pengaruh Ekstrak Daun Pinus (Pinus merkusii Jungh. et de Vriese) terhadap Perkecambahan Vegetatif Tumbuhan Kedelai (Glycine 
max (L.) Merr.). Pasca Sarjana Biologi. Institut Teknologi Bandung. Bandung. Tesis.

[7] Panshin, A.J. dan C. de Zeeuw. 1980. Textbook of Wood Technology. Fourth Edition. Mc. Graw-Hill Book Co. New York.

[8] Perhutani. 2014. Perum Perhutani. http://bumn.go.id/perhutani. Diakses tanggal 4 Mei 2014

[9] Setiawati, W., R. Murtianingsih, G.A Sopha dan T. Handayani. 2007. Budidaya Tanaman Sayuran. Balai Penelitian Tanaman Sayuran. Bandung.

[10] Sitompul, S.M dan D. Purnomo. 2005 Peningkatan Fungsi Agronomi Sistem
Agroforestri Jati, Pinus dengan Penggunaan Varietas Tanaman Jagung Toleran Irradiasi Rendah. Agrosains. 7(2): 93-100.

[11] Sullivan, P. 2003. Intercropping Principles and Production Practices: Agronomy System Guide. http://attra.ncat.org/attrapub/PDF/intercorp.pdf. Diakses tanggal 6 Juni 2015 